\title{
A ALFABETIZAÇÃo, O LETRAMENTO E A DOCÊNCIA: REFLEXÕES NECESSÁRIAS
}

\author{
LITERACY AND TEACHING: NECESSARY REFLECTIONS
}

\begin{abstract}
Andreia Menarbini
Doutoranda em Educação pela Universidade Nove de Julho (UNINOVE), na linha de Políticas Educacionais. Professora da Graduação do Centro Universitário Fundação Santo André.

Santo André, SP - Brasil andreiamenarbini@gmail.com
\end{abstract}

\begin{abstract}
Manuel Tavares
Doutorado em Filosofia pela Universidade de Sevilha. Professor do Programa de Pós-Graduação em Educação (PPGE) da Universidade Nove de Julho (UNINOVE), na linha de Políticas Educacionais.

São Paulo, SP - Brasil

manuel.tavares@outlook.com.br
\end{abstract}

\begin{abstract}
Resumo: O artigo é o resultado da etapa de definição do referencial teórico da pesquisa de doutorado, base incontornável para a fundamentação e contextualização do problema de pesquisa, relacionado com a proposta de alfabetização do Pacto Nacional pela Alfabetização na Idade Certa para a Educação Infantil. Discutimos os conceitos já produzidos que contextualizam a escrita, a leitura, a alfabetização e o letramento, em consonância aos processos e concepções existentes nessas áreas, com a ampliação da discussão para as questões da qualidade da alfabetização, do papel da escola e do docente. Do ponto de vista metodológico, a pesquisa é de tipo qualitativo, documental, com o recurso à análise qualitativa dos dados coletados a partir da análise de discurso.
\end{abstract}

Palavras-chave: Alfabetização. Escrita. Formação de professor. Leitura. Qualidade da educação.

Abstract: The article is the result of the stage of defining the theoretical framework for doctoral research, an essential basis for the foundation and contextualization of the research problem, related to the literacy proposal of the National Pact for Literacy in the Right Age for Early Childhood Education. It sought to discuss the concepts already produced that contextualize writing, reading, and literacy, in line with the processes and concepts existing in these themes, with the expansion of the discussion on issues of the quality of literacy, the role of the school, and the teacher. From a methodological point of view, the research is of a qualitative, documentary type, with the use of qualitative analysis of the collected data, from discourse analysis.

Keywords: Literacy. Quality of education. Teacher training. Writing. Reading.

\section{Para citar - ABNT NBR 6023:2018}

MENARBINI, Andreia; TAVARES, Manuel. A alfabetização, o letramento e a docência: reflexões necessárias. Cadernos de Pós-graduação, São Paulo, v. 19, n. 2, p. 194-206, jul./dez. 2020. Disponível em: https://doi.org/10.5585/cpg.v19n2.18423. 


\section{Introdução}

$\mathrm{Na}$ busca de uma melhor compreensão sobre a temática da alfabetização na Educação Infantil, que é objeto da pesquisa de doutorado, relacionada à proposta de alfabetização do Pacto Nacional pela Alfabetização na Idade Certa para a Educação Infantil, escolhemos autores para com eles refletirmos, do nosso ponto de vista, na perspectiva reflexiva, crítica, problematizante, dialética e desafiante. Nesse sentido, adotamos para essa discussão os autores Freire, Ferreiro, Gadotti e Soares. Também optamos por referenciais que contextualizam a escrita, a alfabetização, o letramento, a docência, bem como os processos e as concepções existentes nessas áreas que são abordados na sequência. Em complemento ao estudo, discorremos sobre a estreita ligação entre a alfabetização com qualidade na escola e o protagonismo docente e, consequentemente, apontamos a necessidade da formação continuada do professor como forma de valorização profissional e de estratégia adequada para a qualidade do ensino. Para tanto, adotamos como metodologia de tipo qualitativo, documental, com recurso à análise qualitativa de dados coletados, a partir da técnica de análise de discurso.

\section{A humanidade e a escrita}

A escrita integra a história da humanidade e é elemento primordial no registro e comunicação das ideias, falas, acontecimentos, tradições, culturas e conhecimentos produzidos pelas diferentes civilizações. Dada a sua relevante importância para a comunicação entre os povos, os historiadores estabeleceram o início da escrita como marco do fim da pré-história e do nascimento da história. Higounet (2003, p.10) esclarece que,

\footnotetext{
A escrita faz de tal modo parte da nossa civilização que poderia servir de definição dela própria. A história da humanidade se divide em duas imensas eras: antes e a partir da escrita. [...] vivemos os séculos da civilização da escrita. Todas as nossas sociedades baseiam-se sobre o escrito. A lei escrita substitui a lei oral, o contrato escrito substituiu a convenção verbal, a religião escrita se seguiu à tradição lendária. E, sobretudo não existe história que não se funde sobre textos.
}

Para que haja escrita é necessária a instituição de sinais preestabelecidos e que representem o sentido utilizado por uma determinada sociedade, possibilitando registrar e reproduzir a oralidade. Desde o surgimento da escrita, inúmeros símbolos e diferentes esquemas de representação de significados foram utilizados para a comunicação humana, diferenciando-se quanto à cronologia, organização e sistematização. Em linhas gerais, a lógica utilizada para a elaboração da escrita pode ser classificada em três etapas, denominadas escrita sintética, analítica e fonética. O autor ainda explica que 
A aquisição desse simbolismo e desse esquematismo se faz por séries de desenvolvimentos mais ou menos lentos e acabados segundo a mentalidade e a língua das sociedades em que são operados. Conservando apenas as grandes linhas, podemos distinguir, porém, entre as tentativas primitivas e o nosso sistema alfabético, três etapas essenciais: escrita sintética, analítica e fonética. (op. cit, p.11)

A escrita sintética foi uma das formas mais primitivas da escrita e caracterizou-se por ser representada por um sinal ou um grupo de sinais que buscaram representar uma frase inteira ou uma ideia contida em uma frase. Já a escrita analítica apresentou uma evolução e passou a representar as palavras. $\mathrm{Na}$ escrita fonética, o homem realizou a notação dos elementos fonéticos de forma silábica ou alfabética. A distinção entre vogais e consoantes dentro das sílabas originou o alfabeto consonantal fenício, que foi o percursor da maioria dos alfabetos atuais, inclusive do nosso, a partir do alfabeto grego.

Em linhas gerais, a evolução do alfabeto como conhecemos hoje, se revela historicamente, conforme Scliar-Cabral (2007, p.30):

\footnotetext{
os proto-sistemas alfabéticos e os alfabéticos originaram-se da escrita sumério-acadiana e dos hieróglifos, evolução esta que resultou nos alfabetos proto-sinaítico (1.500 a.c.), proto-fenício (1.300 a.c.), fenício arcaico (1.100), fenício ou páleo-hebraico (1.000 a.c.), grego (800 a.c.); etrusco ( $800 \sim 700$ a.c.); latino (600 a.c.). o alfabeto moderno data do séc. III.
}

A ordem das letras não mudou, mas novos símbolos surgiram. A princípio, o alfabeto romano era composto por 21 letras. A letra u cumpria a função das letras v, w e u mesmo, enquanto a letra i fazia a função de i e de j, até o século 16, quando o lógico francês Pierre Ramée criou mais letras.

A história da escrita nos mostra os diferentes processos de construção até chegar às escritas de que temos conhecimento. Além da sua relevante importância para uma sociedade letrada, o seu domínio pode abrir caminhos no campo do saber e contribuir para uma participação social mais consciente. Criado o sistema de escrita alfabético, inicia-se outro processo que é o domínio do sistema pelas pessoas para a sua utilização na sociedade em que vivem, o que denominamos de alfabetização. A seguir, propomos uma reflexão sobre as diferentes formas de tratar o processo de alfabetização.

\section{A alfabetização: diferentes interpretações, concepções e abordagens}

A etimologia da palavra alfabetização surgiu da palavra alfabeto, do latim alphabetum, do grego alphábetos, tirado das suas duas primeiras letras, o alfa e o beta. Na língua portuguesa, os portugueses traduziram como Literacia ${ }^{1}$; do inglês literacy, do latim litterätu (culto; sábio), cujo significado 
consiste no aprendizado do alfabeto e de sua utilização como código de comunicação. Essa tradução gerou diferentes interpretações e teorias sobre o significado da alfabetização, originando a palavra letramento.

Inúmeros estudos foram realizados sobre a alfabetização e, a partir deles, constatamos diferentes interpretações, concepções e abordagens de diferentes autores em todo o mundo. Diante dessa constatação, para o estudo proposto, optamos por autores que consideram a alfabetização como direito de todas as pessoas e a concebem como um processo que envolve muito mais do que a aprendizagem dos códigos e de seu funcionamento, e sim como uma forma de interagir, de forma consciente, com as pessoas, a realidade em que vivem e com os conhecimentos construídos pela humanidade.

Entre estes autores, há o que considera o conceito de alfabetização em um único processo abrangente da aprendizagem do sistema de escrita alfabético e a sua utilização na sociedade e outros que utilizam os termos alfabetização e letramento em dois processos diferentes, por meio dos quais a aprendizagem do sistema de escrita alfabético acontece em um processo denominado alfabetização. O processo de comunicação e interação com a sociedade, ocorre em outro sistema chamado de letramento.

Primeiramente, apresentamos a referência principal deste estudo, Paulo Freire, que concebe a alfabetização como um processo único que abrange as pessoas, as relações e a sociedade, cujo sujeito é o alfabetizando. Segundo o autor,

\footnotetext{
Daí que também não pudesse reduzir a alfabetização ao ensino puro da palavra, das sílabas ou das letras. Ensino em cujo processo o alfabetizador fosse "enchendo" com suas palavras as cabeças supostamente "vazias" dos alfabetizandos. Pelo contrário, enquanto ato de conhecimento e ato criador, o processo da alfabetização tem, no alfabetizando, o seu sujeito. (FREIRE, 1989, p.13)
}

Para o autor, a alfabetização é um processo dialógico de interação entre as pessoas e o mundo em que vivem, trazendo possibilidades de compreensão da realidade e de atuação para transformar o que considerarem necessário. A alfabetização é "uma arma” potenciadora de mudanças no sujeito e na sociedade. Ele nos explica que,

[... a leitura do mundo precede sempre a leitura da palavra e a leitura desta implica a continuidade da leitura daquele. Na proposta a que me referi acima, este movimento do mundo à palavra e da palavra ao mundo está sempre presente. Movimento em que a palavra dita flui do mundo mesmo através da leitura que dele fazemos. De alguma maneira, porém, podemos ir mais longe e dizer que a leitura da palavra não é apenas precedida pela leitura do mundo, mas por uma certa forma de "escrevê-lo" ou de "reescrevêlo”, quer dizer, de transformá-lo através de nossa prática consciente. (op. cit, p.13) 
Freire considera a alfabetização como todo o processo de aquisição de conhecimento do sistema de escrita alfabética concomitante à leitura de mundo, que colabora para a elaboração da consciência crítica a partir da realidade em que se vive, oportunizando a emancipação das pessoas e a transformação social.

O trabalho com as palavras do universo vocabular do educando, segundo Freire, traz significações importantes no processo alfabetizador, que vai além da escrita da palavra, já que as palavras que compõem o mundo do educando trazem significações relacionadas ao significado social da palavra e ao seu próprio comportamento, colaborando para a elaboração da consciência reflexiva e crítica humana possibilita que cada um diga a sua própria palavra. Palavra como poder criador, recriador e transformador $\mathrm{O}$ autor nos esclarece,

[...] a alfabetização não é um jogo de palavras, é a consciência reflexiva da cultura, a reconstrução crítica do mundo humano, a abertura de novos caminhos, o projeto histórico de um mundo comum, a bravura de dizer a sua palavra. (FREIRE, 1987, p.10)

Para o autor, a alfabetização é um processo pedagógico amplo, por meio do qual aprender a ler é aprender a dizer a sua palavra. Freire, afirma que a palavra também é ação e o diálogo consciente instituído entre os homens que colaboram para a construção de um mundo comum, a partir de um processo humanizador.

A alfabetização, portanto, é toda a pedagogia: aprender a ler é aprender a dizer a sua palavra. E a sua palavra humana imita a palavra divina: é criadora. A palavra viva é diálogo existencial. Expressa e elabora o mundo, em comunicação e colaboração. O diálogo autêntico - reconhecimento do outro e reconhecimento de si, no outro - é decisão e compromisso de colaborar na construção do mundo comum. Não há consciências vazias; por isto os homens não se humanizam, senão humanizando o mundo. (op, cit, p.11)

O diálogo entre educador e educandos é o pilar do processo de alfabetização além de ser o indicador do conteúdo a ser explorado, pois reflete os anseios e esperanças envolvidos no processo educativo. Tal processo deve ser vivido de forma a conscientizar os envolvidos sobre a realidade em que vivem, promovendo reflexões que possam levar a possíveis mudanças. Conforme o autor,

\footnotetext{
Numa visão libertadora, não mais "bancária” da educação, o seu conteúdo programático já não involucra finalidades a serem impostas ao povo, mas, pelo contrário, porque parte e nasce dele, em diálogo com os educadores, reflete os seus anseios e esperanças. (op, cit, p. 59)
}

Nessa perspectiva progressista da alfabetização, a compreensão da linguagem é primordial, já que é a partir dela que se conquista uma percepção mais crítica do mundo, que se torna um caminho de possibilidades para reescrever a história e transformá-la em prol dos próprios homens. 
Freire (1992, p. 22) refere: "Daí, também, a necessidade, nos trabalhos de alfabetização numa perspectiva progressista, de uma compreensão da linguagem e de seu papel, antes referido na conquista da cidadania." O autor ainda afirma que, "Ler o mundo é um ato anterior à leitura da palavra. O ensino da leitura e da escrita da palavra a que falte o exercício crítico da leitura e da releitura do mundo é, científica, política e pedagogicamente capenga.” (FREIRE, 1992, p. 41). Freire (op, cit, p.102) defende que pela natureza social da aquisição da linguagem, a alfabetização nunca poderá dicotomizar-se do processo político da luta pela cidadania.

Soares (2004, p.96) considera dois processos diferenciados: a alfabetização e o letramento. Esclarece a autora que alfabetização escolar no Brasil é marcada por inúmeras mudanças conceituais e metodológicas, decorrentes das necessidades apresentadas pelo fracasso escolar e pelas inúmeras tentativas dos profissionais da área em resolver o problema. Assim sendo, coloca como necessário esclarecer e relacionar os termos alfabetização e letramento, para a explicação dos caminhos e descaminhos percorridos no país sobre a temática. A autora explicita que,

[...] é necessário reconhecer que alfabetização - entendida como a aquisição do sistema convencional de escrita - distingue-se de letramento - entendido como o desenvolvimento de comportamentos e habilidades de uso competente da leitura e da escrita em práticas sociais: distinguem-se tanto em relação aos objetos de conhecimento quanto em relação aos processos cognitivos e linguísticos de aprendizagem e, portanto, também de ensino desses diferentes objetos. Tal fato explica por que é conveniente a distinção entre os dois processos. Por outro lado, também é necessário reconhecer que, embora distintos, alfabetização e letramento são interdependentes e indissociáveis: a alfabetização só tem sentido quando desenvolvida no contexto de práticas sociais de leitura e de escrita e por meio dessas práticas, ou seja, em um contexto de letramento e por meio de atividades de letramento; este, por sua vez, só pode desenvolver-se na dependência da e por meio da aprendizagem do sistema de escrita. (op. cit, p. 97)

Outra concepção é a de Emília Ferreiro (2003) que, em entrevista à revista Nova Escola, defende a concepção de que a alfabetização não precede o letramento e que os dois processos podem ser simultâneos, embora independentes e que a coexistência de ambos não funciona, pois são processos de natureza diferente. A autora rejeita a coexistência dos dois processos com o argumento de que a alfabetização compreende o conceito de letramento, ou vice-versa. Ferreiro (1996, p.24), por sua vez, afirma que "o desenvolvimento da alfabetização ocorre, sem dúvida, em um ambiente social. Mas as práticas sociais assim como as informações sociais não são recebidas passivamente pelas crianças." Contrariando essa perspectiva, segundo a autora, muitos professores ainda definem o processo de alfabetização como sinônimo de uma técnica ou método de ensino. Nas pesquisas realizadas, Ferreiro procurou observar como se realiza a construção da linguagem escrita na criança e os resultados obtidos indicaram que ao se conhecer a maneira como a criança concebe o processo de escrita e as teorias pedagógicas e metodológicas, se possa apontar o caminho 
para a aprendizagem. Em sua principal obra A Teoria da Psicogênese da Lingua Escrita, de 1985, provoca uma revolução quanto à concepção de alfabetização, pois demonstra que o conhecimento é algo a ser produzido pelo indivíduo, o que o torna sujeito e não objeto do processo de aprendizagem.

Os autores apresentados consideram a alfabetização como um processo de grande relevância para todas as pessoas, uma vez que ela contribui para a emancipação do sujeito possibilitando a mobilidade social. Todavia, para que esse processo ocorra é necessária uma alfabetização com qualidade, isto é, uma aprendizagem que considere os aprendizes como sujeitos, a partir da realidade que vivenciam e amplie as suas percepções individuais e sobre o coletivo social. É essa perspectiva que trataremos no próximo tópico.

\section{A estreita ligação entre a alfabetização com qualidade na escola e o protagonismo docente}

A questão da alfabetização não pode ser discutida e trabalhada esquecendo a sua qualidade. Nesse sentido, Paulo Freire nos esclarece que o conceito de qualidade da alfabetização envolve todo o processo educacional que, consequentemente, engloba toda a sociedade e seus processos econômicos, políticos e sociais; a escola, os professores e a formação dos professores. O processo educativo sofre constantemente influências internas e externas à escola que se modificam conforme o contexto histórico, político e social. Assim sendo, o conceito qualidade da educação sofre modificações, conforme a dinâmica social e o entendimento político do próprio significado de educação. Na perspectiva de Gadotti (2013, p.4) a qualidade da educação, atualmente, se relaciona ao conceito de educação sociocultural. $\mathrm{O}$ autor refere:

\footnotetext{
Quando a escola pública era para poucos, era boa só para esses poucos. Agora que é de todos, principalmente para os mais pobres, ela precisa ser apropriada para esse novo público, ela deve ser de qualidade sociocultural. Isso significa investir nas condições que possibilitam essa nova qualidade que inclui transporte, saúde, alimentação, vestuário, cultura, esporte e lazer. Não basta matricular os pobres na escola (inclusão). É preciso matricular com eles, também, a sua cultura, seus desejos, seus sonhos, a vontade de "ser mais" (Freire). É preciso matricular o projeto de vida desses novos alunos numa perspectiva ética, estética e ecopedagógica. A educação integral precisa visar à qualidade sociocultural da educação, que é sinônimo de qualidade integral.
}

A educação sociocultural é um conceito que deve estar presente nas políticas educacionais, na escola, na prática dos professores e profissionais da educação, e na formação docente e foi tomado em consideração na nossa pesquisa. Nesta perspectiva, a escola se torna um espaço privilegiado para o desenvolvimento da educação para todos e pode contribuir para o processo de transformação social, dependendo das opções pedagógicas e compromisso social assumido perante 
toda a comunidade escolar. Tratando da questão, Freire (1992, p.58) concebe uma escola antitradicionalista, conforme trata no trecho a seguir:

\begin{abstract}
É uma escola em que realmente se estude e se trabalhe. Quando criticamos, ao lado de outros educadores, o intelectualismo de nossa escola, não pretendemos defender posição para a escola em que se diluíssem disciplinas de estudo e uma disciplina de estudar. Talvez nunca tenhamos tido em nossa história necessidade tão grande de ensinar, de estudar, de aprender mais do que hoje. De aprender a ler, a escrever, a contar. De estudar história, geografia. De compreender a situação ou as situações do país. O intelectualismo combatido é precisamente esse palavreado oco, vazio, sonoro, sem relação com a realidade circundante, em que nascemos, crescemos e de que ainda hoje, em grande parte, nos nutrimos. Temos de nos resguardar deste tipo de intelectualismo como também de uma posição chamada antitradicionalista que reduz o trabalho escolar a meras experiências disso ou daquilo e a que falta o exercício duro, pesado, do estudo sério, honesto, de que resulta uma disciplina intelectual.
\end{abstract}

Freire propõe a escola como um local de ensino e de aprendizagem, mobilizada a partir da organização das pessoas para e com as pessoas, cujo fluxo de debates promova reflexões conjuntas do fazer pela própria experiência, em consonância com os conhecimentos acumulados pela humanidade. Dessa forma, a participação é determinante para o êxito dos processos de ensino e de aprendizagem, e à escola e ao professor cabem o papel de organizadores das ações participativas dos alunos e comunidade, em prol de uma educação em que o homem se constitua enquanto sujeito social atuante na história:

[...] é preciso que a educação esteja - em seu conteúdo, em seus programas e em seus métodos - adaptada ao fim que se persegue: permitir ao homem chegar a ser sujeito, construir-se como pessoa, transformar o mundo, estabelecer com os outros homens relações de reciprocidade, fazer a cultura e a história [...] uma educação que liberte, que não adapte, domestique ou subjugue. (FREIRE, 1979, p. 21)

Nessa concepção, o professor assume o protagonismo no planejamento e no desenvolvimento do trabalho educativo, estruturado a partir da participação e do diálogo, num movimento contínuo de ação-reflexão-ação. Segundo o autor, a relação teoria e prática é indissociável e na ação pedagógica deve ser organizada por meio do diálogo e da conscientização, como o próprio nos esclarece: “A conscientização não pode existir fora das "práxis", ou melhor, sem o ato ação-reflexão. Esta unidade dialética constitui de maneira permanente, o modo de ser ou de transformar o mundo que caracteriza os homens.” (FREIRE, 1979, p. 15)

Os professores têm papel determinante no processo educativo e o seu sucesso está correlacionado à conscientização do professor sobre o seu papel, compromisso com a educação e com a sociedade, seus conhecimentos, com a coerência de suas ações profissionais. "[...] se o meu compromisso é realmente com o homem concreto, com a causa de sua humanização, de sua libertação, 
não posso por isso mesmo prescindir da ciência, nem da tecnologia, com as quais me vou instrumentando para melhor lutar por esta causa.” (FREIRE, 2007, p. 22) As ações dos educadores no processo educativo são de grande abrangência, por isso, estes profissionais precisam estudar, buscar diferentes saberes e informações, além de se posicionarem frente ao mundo em que vivem, para poderem fazer escolhas pessoais e profissionais cada vez mais conscientes, já que as suas escolhas influenciam a sua própria vida, a de seus educandos e da comunidade em que atuam.

\footnotetext{
Você, eu, um sem-número de educadores sabemos todos que a educação não é a chave das transformações do mundo, mas sabemos também que as mudanças do mundo são um que fazer educativo em si mesmas. Sabemos que a educação não pode tudo, mas pode alguma coisa. Sua força reside exatamente na sua fraqueza. Cabe a nós pôr sua força a serviço de nossos sonhos. (FREIRE, 1991, p. 126)
}

Quanto maior for a clareza do professor sobre o significado da educação, do seu papel e o compromisso com o homem, as suas escolhas podem contribuir para uma transformação social. Ressalta-se que a transformação social não ocorre somente pela educação, mas as ações e o posicionamento de seus profissionais podem auxiliar as mudanças necessárias para uma sociedade mais justa, respeitosa e igualitária. É necessário que o professor, ao escolher essa profissão, tenha a clareza de que trabalha com pessoas. É a partir da relação estabelecida com o aluno e comunidade/mundo que exerce um papel importante em suas vidas, podendo, assim, por meio do diálogo e da participação, abrir novos horizontes para os educandos, criando possibilidades para que eles se tornem sujeitos autônomos, agentes do seu próprio desenvolvimento, aptos para participarem ativa e conscientemente na sociedade. Nessa perspectiva, conceber a educação como instrumento de transformação social pressupõe que as pessoas construam a sua própria história e que, por intermédio das relações e dos diálogos que mantêm, sejam capazes de problematizar as suas relações com o mundo, se posicionando e se relacionando com as demais pessoas com mais respeito, tolerância e solidariedade. Dada a importância do papel do professor, urge cuidar da sua formação como uma das formas de o valorizar profissionalmente e contribuir para a qualidade da educação. Em seguida, abordaremos alguns aspectos sobre a formação docente.

\section{A profissão de professor e a importância da formação continuada}

A profissão de professor exige constantes atualizações profissionais, científicas e pedagógicas que, geralmente, são realizadas no formato de formação continuada ou formação permanente. $\mathrm{Na}$ concepção freiriana, são nomeadas como formação permanente, pois, para Freire (1991), o professor é um profissional em permanente construção, que se faz e se refaz a partir de sua prática, 
por intermédio de reflexões sobre o seu cotidiano e cuja prática depende da compreensão do processo de conhecimento.

O autor trouxe contribuições de extrema importância quanto ao conceito de formação permanente dos professores que aqui procuramos contemplar. Quando foi Secretário de Educação da cidade de São Paulo, Paulo Freire desenvolveu um programa de formação de professores, em que foram apresentados como princípios de formação:

1) o educador é o sujeito de sua prática, cumprindo a ele criá-la e recriá-la;

2) a formação do educador deve instrumentalizá-lo para que ele crie e recrie a sua prática através da reflexão sobre o seu cotidiano;

3) a formação do educador deve ser constante, sistematizada porque a prática se faz e se refaz;

4) a prática pedagógica requer a compreensão da própria gênese do conhecimento, ou seja, de como se dá o processo de conhecer;

5) o programa de formação de educadores é condição para o processo de reorientação curricular;

6) o programa de formação de educadores terá como eixos básicos: a fisionomia da escola que se quer, enquanto horizonte da nova proposta pedagógica; a necessidade de suprir elementos de formação básica aos educadores nas diferentes áreas do conhecimento humano; a apropriação, pelos educadores, dos avanços científicos do conhecimento humano que possam contribuir para a qualidade da escola que se quer. (FREIRE, 1991, p. 80)

Esses princípios indicam, que ao organizar a formação de professores, é preciso considerar que o professor é um profissional que age a partir de sua identidade e é o sujeito de sua prática. É importante destacar que a identidade do professor integra um processo permanente de construção e que, atualmente, a identidade tradicional desses profissionais está comprometida com as exigências da mercadorização da educação. Dubar (2005, p.330) explicita que

[...] as identidades sociais e profissionais típicas não são nem expressões psicológicas de personalidades individuais nem produtos de estruturas ou de políticas econômicas impostas de cima, mas sim construções sociais que implicam a interação entre trajetórias individuais e sistemas de emprego, de trabalho e de formação. Resultados sempre precários ainda que muito fecundos de processos de socialização, essas identidades constituem formas sociais de construção de individualidades, a cada geração, em cada sociedade.

Tais exigências mercadológicas podem desviar o foco das reais necessidades dos alunos e o professor corre o risco de se tornar um mero condutor de pessoas em um processo educativo organizado para o atendimento das exigências do mercado, contribuindo para a reprodução das desigualdades e injustiças sociais.

Assim sendo, é necessário trabalhar na formação o aprimoramento do olhar do professor sobre a escola e sobre a comunidade e contextos em que a escola está inserida. A centralidade dos alunos na prática pedagógica, a valorização dos conhecimentos produzidos pela humanidade, as 
ações colaborativas, bem como a permanente reflexão sobre a prática pedagógica constituem princípios fundamentais potenciadores da mudança educativa. Esclarece Freire (1996, p.26) que: “O que importa, na formação docente, não é a repetição mecânica do gesto, este ou aquele, mas a compreensão do valor dos sentimentos, das emoções, do desejo, da insegurança a ser superada pela segurança, do medo que, ao ser 'educado', vai gerando a coragem.”

Trabalhar nessa perspectiva, exige também consciência social do formador de professor, uma vez que grande parte dos programas de formação dos professores e proposituras das secretarias de educação se organizam a partir de políticas de governo e não de estado, as quais trazem viés ideológico compromissado com as administrações vigentes, desconsiderando a realidade das escolas. Dessa forma, o formador deve assumir um papel crítico, dando voz aos professores para que possam expressar suas ideias e necessidades e, a partir delas, desenvolver os seus encontros formativos junto aos conteúdos que foram propostos.

Considerando as reflexões apresentadas, é possível constatar que a escola e o professor estão intrinsicamente ligados e a educação libertadora só ocorrerá por meio da participação de professores em colaboração com os alunos, comunidade escolar, unidos pelo desejo de mudança e transformação social. O autor contribui afirmando: "O sonho de mudar a cara da escola. O sonho de democratizá-la, de superar o seu elitismo autoritário, o que só pode ser feito democraticamente." (FREIRE, 1991, p. 74); “O sonho que tem que ver com uma sociedade menos injusta, menos malvada, mais democrática, menos discriminatória, menos racista, menos sexista.” (op, cit, p. 118)

Por meio das reflexões aqui descritas concluímos que a qualidade da educação é um conceito sistêmico, em permanente construção social que envolve a escola, o professor, os profissionais, os alunos, a comunidade escolar, a formação permanente, as propostas educacionais e os processos sociais, políticos e culturais. Para analisá-lo é necessário observar todos os segmentos que envolvem a educação, desde as concepções e as influências históricas, econômicas, políticas e culturais que compõem o processo educativo, para que se obtenha uma visão real da educação que está sendo pretendida, desenvolvida e praticada.

\section{Considerações finais}

A alfabetização é um tema complexo que se relaciona aos fatores sociais, políticos, econômicos existentes na sociedade. Sendo assim, há de se destacar os jogos de interesses, por parte da classe dominante, na perspectiva de dominação dos grupos sociais desfavorecidos economicamente, em que a preocupação de alfabetizar se relaciona apenas à qualificação da mão de obra para o mercado de trabalho. Nessa direção, há de se considerar que alfabetização não deve ser encarada como um mero ato ou processo instrumental, no qual se aprenda apenas decodificar códigos. Mas 
implica numa responsabilidade social, em que a escola e os professores assumem papel determinante em relação à qualidade da educação, dado que são os atores sociais diretamente responsáveis pelo processo de aquisição da leitura e da escrita por parte dos educandos. Quanto mais especializados e conscientes sobre o processo de alfabetização e de seus papéis na sociedade, poderão mais bem atuar em prol de uma educação de qualidade para a emancipação das pessoas, contribuindo para uma sociedade mais justa, respeitosa e solidária. Ler e escrever é elemento fundante e primordial para o exercício de uma cidadania consciente e crítica, além de ser um fator de inclusão numa sociedade democrática.

Nessa perspectiva, questionamos: o que obstaculiza a aprendizagem da leitura e escrita por vários alunos matriculados na educação básica? As escolas e os professores têm tido a autonomia necessária para realizarem as suas propostas de alfabetização, ou estão sendo forçados pelos sistemas de ensino a praticarem propostas descontextualizadas que pouco contribuem para esse processo tão fundamental para os estudantes? As políticas educacionais têm considerado as indicações dos professores e das escolas para a sua formulação, ou são organizadas a partir de alguns grupos de pessoas pertencentes aos governos, que as formulam segundo as suas próprias concepções e interesses políticos? As políticas educacionais estão sendo organizadas em prol da aprendizagem de todos, ou só para determinadas camadas sociais, conforme interesses econômicos e políticos?

O esclarecimento dessas questões poderia favorecer a compreensão da alfabetização em seu sentido amplo e auxiliar na construção de novos conhecimentos sobre a temática, além de contribuir com fundamentos a serem considerados para a elaboração de novas políticas públicas e ou reorganização das existentes, na perspectiva de respeitar a realidade das escolas, as culturas locais e regionais e o repertório profissional dos professores, contribuindo para o aprimoramento do processo de alfabetização, de forma mais eficiente e respeitosa aos percursos pessoais dos estudantes e profissionais dos professores.

\section{Nota}

${ }^{1}$ Literacia in Dicionário Infopédia da Língua Portuguesa [em linha]. Porto: Porto Editora, 2003-2018. Disponível na Internet: https://www.infopedia.pt/dicionarios/lingua-portuguesa/literacia. Acesso em: 29 jul. 2018.

\section{Referências}

DUBAR, Claude. A Socialização - Construção das Identidades Sociais e Profissionais Tradução: Andréa Stabel M. da Silva. São Paulo, SP, Martins Fontes, 2005.

FERREIRO, Emilia. Alfabetização em Processo. São Paulo: Cortez, 1996. 
FERREIRO, Emilia. Alfabetização e cultura escrita. Revista Nova Escola impressa n. 162, maio 2003.

FREIRE, Paulo. A Educação na Cidade. 3.ed. São Paulo: Cortez, 1991.

FREIRE, Paulo. A importância do ato de ler: em três artigos que se completam. 15. ed. São Paulo: Cortez/Autores Associados, 1989.

FREIRE, Paulo. Conscientização: teoria e prática da libertação: uma introdução ao pensamento de Paulo Freire / Paulo Freire; [tradução de Kátia de Mello e silva; revisão técnica de Benedito Eliseu Leite Cintra]. São Paulo: Cortez \& Moraes, 1979.

FREIRE, Paulo. Educaşão e mudança. 30ª ed.; Rio de Janeiro: Paz e Terra, 2007.

FREIRE, Paulo. Pedagogia do Oprimido. 17.ed. Rio de Janeiro: Paz e Terra, 1987.

FREIRE, Paulo. Pedagogia da Esperança: Um reencontro com a Pedagogia do Oprimido / Paulo Freire. - Notas: Ana Maria Araújo Freire Rio de Janeiro: Paz e Terra, 1992.

GADOTTI, Moacir. A qualidade na Educação: uma nova abordagem. In: Congresso de Educação Básica. Rede Municipal de Florianópolis (SC). 2013. Disponível em:

http://www.pmf.sc.gov.br/arquivos/arquivos/pdf/14_02_2013_16.22.16.85d3681692786726aa2c7daa4389040f.pdf. Acesso em: 28 set. 2018.

HIGOUNET, Charles. História concisa da escrita. 10ª edição - São Paulo: Parábola Editorial, 2003.

SCLIAR-CABRAL, Leonor. Processos metonímicos na evolução do alfabeto. Revista da ABRALIN, [S.l.], v. 6, n. 2, may 2017. ISSN 0102-7158. Disponível em: https:/ / revistas.ufpr.br/abralin/article/view/52622. Acesso em: 26 nov. 2020. DOI:

http://dx.doi.org/10.5380/rabl.v6i2.52622.

SOARES, Magda Becker. Alfabetização e Letramento: caminhos e descaminhos. UNESP. Acervo digital. Univesp - São Paulo: Cultura Acadêmica, 1996. Disponível em: https:/ / acervodigital.unesp.br/bitstream/123456789/40142/1/01d16t07.pdf. Acesso em: 05 jun. 2020.

SOARES, Magda Becker. Letramento e alfabetização: as muitas facetas. Universidade Federal de Minas Gerais, Centro de Alfabetização, Leitura e Escrita

2004. Disponível em: http://www.scielo.br/pdf/rbedu/n25/n25a01.pdf. Acesso em: 02 jun. 2020. 